TI 2012-040/3

Tinbergen Institute Discussion Paper
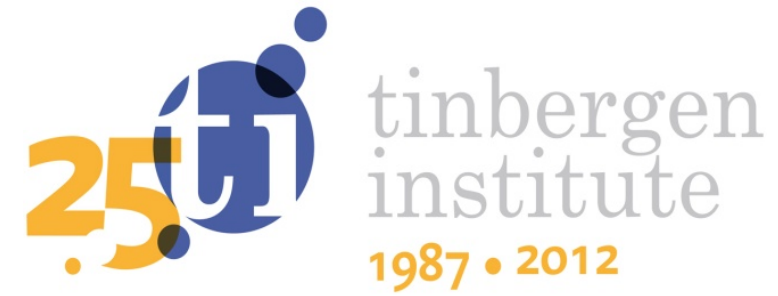

\title{
The On-Street Parking Premium and Car Drivers' Choice between Street and Garage Parking
}

\author{
Martijn Kobus \\ Eva Gutierrez-i-Puigarnau \\ Piet Rietveld \\ Jos Van Ommeren
}

Faculty of Economics and Business Administration, VU University Amsterdam, and Tinbergen Institute. 
Tinbergen Institute is the graduate school and research institute in economics of Erasmus University Rotterdam, the University of Amsterdam and VU University Amsterdam.

More TI discussion papers can be downloaded at http://www.tinbergen.nl

Tinbergen Institute has two locations:

Tinbergen Institute Amsterdam

Gustav Mahlerplein 117

1082 MS Amsterdam

The Netherlands

Tel.: +31(0)205251600

Tinbergen Institute Rotterdam

Burg. Oudlaan 50

3062 PA Rotterdam

The Netherlands

Tel.: +31(0)10 4088900

Fax: $+31(0) 104089031$

Duisenberg school of finance is a collaboration of the Dutch financial sector and universities, with the ambition to support innovative research and offer top quality academic education in core areas of finance.

DSF research papers can be downloaded at: http://www.dsf.nl/

Duisenberg school of finance

Gustav Mahlerplein 117

1082 MS Amsterdam

The Netherlands

Tel.: +31(0)20 5258579 


\title{
The on-street parking premium and car drivers' choice between street and garage parking
}

\author{
Martijn Kobus* \\ Eva Gutiérrez-i-Puigarnau
}

Piet Rietveld

Jos Van Ommeren

VU University, FEWEB, De Boelelaan, 1081 HV Amsterdam, the Netherlands

$17 / 04 / 2012$

Abstract. We introduce a methodology to estimate the effect of parking prices on car drivers' choice between street and garage parking. Our key identifying assumption is that the marginal benefit of parking duration does not depend on this choice. The endogeneity of parking duration is acknowledged in the estimation procedure. We apply the methodology to an area where cruising for parking is absent, street parking is ubiquitous and garage parking is discretely located over space. So, in this area, the average distance to the final destination is longer for garage parking than for street parking. We find that drivers are willing to pay a premium for street parking which ranges from $€ 0.35$ to $€ 0.58$. Given a parking duration of one hour, we find that the demand for street parking is extremely price elastic: the price elasticity of demand for the share of street parking is -4 . However, the price elasticity is much smaller for shorter parking durations. Our estimates imply that even small reductions in street parking prices induce a strong increase in the stock of cars parked on-street. Our estimates also imply that a policy which contains an onstreet premium (so street prices exceed garage prices) is welfare improving, because drivers with longer parking durations are induced to use parking locations that are, on average, farther away.

*Corresponding author. E-mail address: m.b.w.kobus@vu.nl. Jos Van Ommeren and Piet Rietveld are affiliated with the Tinbergen Institute, Amsterdam. Gutiérrez-i-Puigarnau would like to thank Netherlands Organisation for Scientific Research (NWO) for funding. We would like to thank the municipality of Almere and Spark, and in particular Ernst Bos and Rob Ebbing, for providing access to parking transactions data. 


\section{Introduction}

Pricing of street parking has come to the fore in the economic literature since the seminal paper by Vickrey (1969). One of the main results is that cruising is seen as an inherent welfare loss for society, which should be eliminated by a pricing policy (Shoup, 2005; Arnott and Inci, 2006). ${ }^{1}$ It is suggested that when street and garage parking are perfect substitutes and the garage parking market is perfectly competitive, street prices must equal garage prices in order to eliminate cruising (Calthrop, 2001; Calthrop and Proost, 2006). ${ }^{2}$

In reality however street and garage parking are not perfect substitutes, because of spatial differences in parking supply, as emphasised by Arnott and Rowse (2009). For instance, in centres of Dutch cities, shops and street parking are usually ubiquitous, whereas garage parking is discretely supplied over space due to economies of scale in garage parking (e.g. Arnott, 2006). In this case, one expects that shoppers prefer street parking as it is, on average, closer to their final destination. ${ }^{3}$ So, given equal prices for street and garage parking (and no spatial variation in parking prices), cruising for parking may still occur. ${ }^{4}$

The theoretical economics of parking literature analyses the drivers' choice on where to park, the choice between street and garage parking and the distortionary effects of nonoptimal pricing (e.g. Arnott et al., 1991; Arnott et al., 2012). However, we are not aware of any empirical study which estimates the effect of street prices on drivers' choice between

\footnotetext{
${ }^{1}$ Anderson and de Palma (2004) show that when drivers have imperfect information about parking vacancies, on-street parking prices should not completely eliminate cruising.

${ }^{2}$ Given on-street cruising, commercial garage parking operators may have monopsonistic power (Arnott, 2006). This may explain why in many cities around the world, the commercial garage parking market is regulated.

${ }^{3}$ Although this description of a shopping area is standard for the Netherlands (and many other European countries), it is different in other parts of the world. In Asia, for example, street parking in urban areas is rare (ADB, 2010). In the US, garages are usually integrated into shopping malls (Hasker and Inci, 2011), so street parking is on average farther away from drivers' final destinations. ${ }^{4}$ This effect may even be stronger when garage parking requires additional driving and walking time within the building.
} 
street and garage parking. ${ }^{5}$ As a result, we currently have little knowledge to what extent differences between street and garage parking prices affect this parking choice.

In the current paper, we aim to contribute to the literature on the effect of on-street parking prices on welfare. ${ }^{6}$ To this end, we introduce an easy-to-implement methodology to estimate drivers' willingness to pay for street parking (relative to garage parking). We implement this methodology using information from administrative data about parking durations for one particular city in the Netherlands. The kind of administrative data used in the current study is widely available in many cities around the world (see, e.g., Kelly and Clinch, 2009). So, one of the advantages of our methodology is that it can easily be applied to other cities.

In essence, in our methodology we make use of differences in prices between street parking and garage parking per time unit. We are able to identify the effect of prices on the choice between street and garage parking using information on driver parking durations. Our key identifying assumption is that the driver's marginal benefit of duration does not depend on this parking choice. So, parking choice is a function of parking duration, because drivers face different pricing schemes for garage and street parking. Because the duration of parking is self-chosen, its endogeneity will be taken into account in the estimation procedure.

We apply this methodology to the choice between street and garage parking in the Central Business District (CBD) of the city of Almere in the Netherlands (located about 20 $\mathrm{km}$ east of Amsterdam). This city has about 200,000 inhabitants. Almere is a rather young city: it has been built, starting in the $70 \mathrm{~s}$, on land gained from the sea. Nowadays, Almere is the fastest growing city in the Netherlands. Its urban structure deviates from most European

\footnotetext{
${ }^{5}$ Revealed preference studies on parking include Gillen (1978), van der Goot (1981), Kelly and Clinch (2006), Van Ommeren et al. (2011) and van Ommeren and Wentink (2012). For stated preference studies, we refer to Axhausen and Polak (1991), Hensher and King (2001), and Golias et al. (2002).

${ }^{6}$ Recently, a dynamic street pricing scheme has been introduced in San Francisco, which is unique in the world. Such a scheme may vary street prices optimally over space. The current study focuses on a second-best alternative more typically found when, due to political or technical feasibility, policy makers set spatially uniform on-street prices.
} 
cities that have historic centres and resembles the stylised monocentric structure of cities often described in urban economics textbooks. Shopping and parking for non-residents is concentrated in the CBD. The CBD is surrounded by a residential area where non-residential parking is prohibited. The residential area is again surrounded by a rural industrial activity area, which is too far to walk from the $\mathrm{CBD}$. Although the $\mathrm{CBD}$ contains a very large concentration of shops, ${ }^{7}$ it is rather small in terms of geographical size (i.e., slightly smaller than 3 square kilometres).

Because Almere has no historic centre, it is not attractive for tourists, which makes it likely that most drivers regularly visit Almere, and are therefore well-informed about its parking locations and pricing policy. The local government has fully regulated street and garage parking. Within the CBD, there is no spatial variation in parking prices. Street parking is 33 percent more expensive than garage parking, so there is a premium for parking on-street. There is excess supply of both street and garage parking at most times of the day (given current prices), except for peak hours on Saturdays which we exclude from our analysis. ${ }^{8}$ As a result, there is essentially no cruising for street parking (in line with a recent study for other Dutch cities, see Van Ommeren et al., 2012). ${ }^{9}$ Therefore, it is reasonable to assume that drivers usually park at their preferred location.

In our application, we focus on a part of the CBD where shops and street parkings are ubiquitous (so, most shopping streets have street parking). The area also contains six garage parkings that are discretely located over space. Three of these garage parkings are within 100 meters of each other, so there are essentially only four distinct garage locations. The distance

\footnotetext{
${ }^{7}$ The Almere CBD has the second largest concentration of shops in the Netherlands.

${ }^{8}$ Although there is overcapacity most of the time, this does not imply that there is structural excess supply, because the marginal willingness to pay for parking on peak hours may not be less than the marginal cost of parking.

${ }^{9}$ Studying parking behaviour when cruising is absent is also very relevant for the cruising for parking literature. The current study will show that an on-street parking premium may be required to eliminate cruising in situations where street and garage parking are not perfect substitutes.
} 
between these garage locations is about 500 meter. A map of this part of the CBD indicating these six garage locations is provided in Figure 1.

The structure of this paper is as follows. Section 2 presents a choice model for individual drivers and an empirical approach to estimate the effect of prices on choice between street and garage parking. Section 3 discusses the Almere parking data and provides descriptive statistics. Section 4 presents the empirical results. Section 5 is a sensitivity analysis, and section 6 concludes.

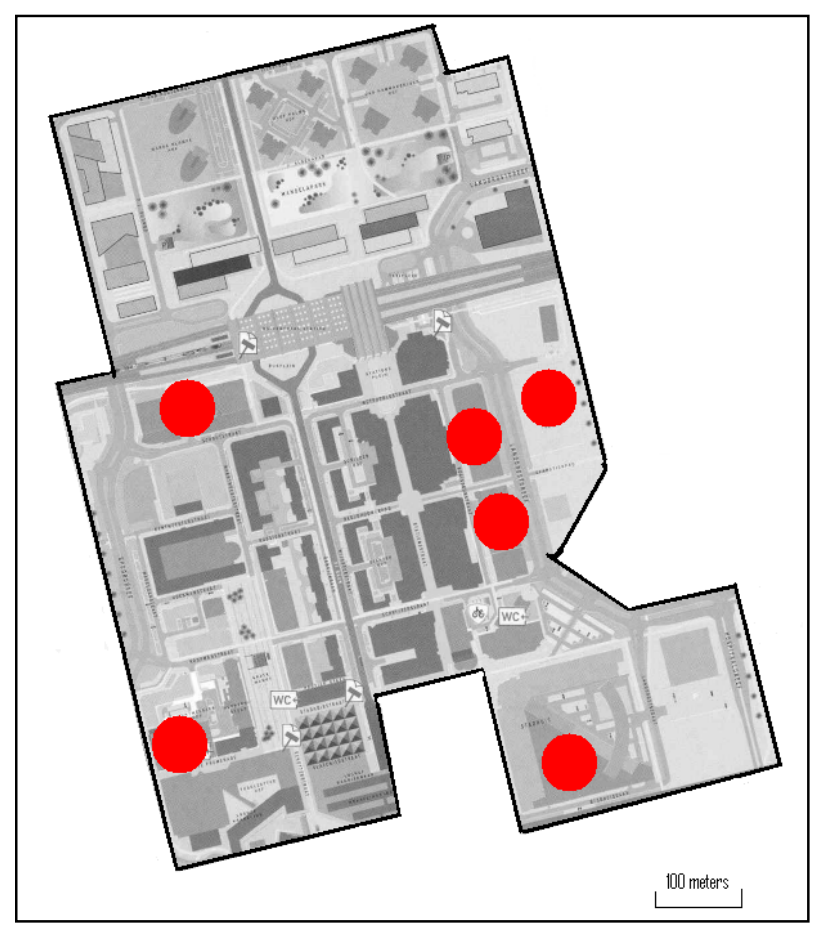

Figure 1: Map of Almere CBD (circles denote garages).

\section{Theoretical model and estimation procedure}

\subsection{Theoretical model on parking choice}

We focus on a driver who chooses between street and garage parking. The (indirect) utility function $f$ for parking choice is defined by:

$$
U_{i}=f\left(p_{i}\left(d_{i}\right), d_{i}, \alpha_{i}, \varepsilon_{i}\right) .
$$


where $i=s, g$ defines street or garage parking and $U_{i}$ is the indirect utility. Here, $p_{i}$ denotes the price of parking, $d_{i}$ denotes the parking duration and $\alpha_{i}$ is an unknown parameter which measures the type-specific benefits (or costs). ${ }^{10}$ In particular, $\alpha_{i}$ captures the walking time to the driver's final destination, which usually differs between street and garage parking locations. ${ }^{11}$ The error term $\varepsilon$ is a stochastic and unobserved component. Note that in (1), the price of parking depends on the duration of parking, so $p_{i}=p_{i}\left(d_{i}\right)$. We assume for now that the duration is exogenous, so $d_{s}=d_{g}=d$. Importantly, the endogeneity of duration will be fully acknowledged in the empirical analysis. We put standard restrictions on the functional form of $f$. We will assume that $f$ is an additive separable function, and rewrite $f$ as a linear-inparameter function, so:

$$
U_{i}=\alpha_{i}+\beta p_{i}(d)+g(d)+\varepsilon_{i}
$$

where $g(d)$ is an arbitrary function and $\varepsilon$ has expectation zero. In this specification, $\beta$ captures the effect of the parking price, so $\beta<$ zero, and $g(d)$ captures the benefits of parking duration. Note that $g(d)$ does not depend on $i$. So, the marginal benefits of parking duration are independent of the choice between street and garage parking. ${ }^{12}$ The driver will choose to park on-street when $U_{s} \geq U_{g}{ }^{13}$ So, the probability of street parking, $P_{s}$, can be written by:

$$
P_{s}=\operatorname{Prob}\left(\alpha_{s}-\alpha_{g}+\beta\left[p_{s}(d)-p_{g}(d)\right]+\varepsilon_{s}-\varepsilon_{g}>0\right) .
$$

The parameters of interest, $\alpha_{s}-\alpha_{g}$ and $\beta$, can be estimated given assumptions on the distribution of $\varepsilon$ (i.e., a normal distribution). So, (3) can be rewritten as:

$$
P_{s}=\operatorname{Prob}\left(\alpha+\beta\left[p_{s}(d)-p_{g}(d)\right]+\varepsilon>0\right)
$$

\footnotetext{
${ }^{10} \mathrm{We}$ are aware that there may be uncertainty about the duration of parking. This may influence the choice between street and garage parking. We come back to this in section 2.2.

${ }^{11}$ This interpretation is consistent with Golias et al. (2002) who report that all determinants for the choice between street and garage parking are related to monetary parking costs and time-savings, whereas other determinants are not found to be statistically significant. There are however likely also other, less important, reasons why drivers may have a preference for a certain parking type. For example, drivers may prefer garage parking, because it allows to pay afterwards.

${ }^{12}$ This assumption seems reasonable in our context where safety issues (i.e., car theft or damage) do not play a role, because the marginal benefit of parking duration is then parking choice specific.

${ }^{13}$ This is a common assumption, but may not hold if drivers are not well-informed.
} 
where $\alpha=\alpha_{s}-\alpha_{g}$ measures the benefits of street parking (relative to garage parking) and $\varepsilon=$ $\varepsilon_{s}-\varepsilon_{g}{ }^{14}$ In our application, it appears that $p_{s}$ and $p_{g}$ are both proportional to $d$ (up to a certain maximum). In this case, (4) can be rewritten as:

$$
P_{s}=\operatorname{Prob}(\alpha+\beta d D+\varepsilon>0) \text {, }
$$

where $p_{s}(d)-p_{g}(d)=D d$, and where $D$ denotes the price difference between street and garage parking per unit of time. For the driver, $D$ is given, so one may rewrite (5) as:

$$
P_{s}=\operatorname{Prob}(\alpha+\theta d+\varepsilon>0)
$$

where $\theta=\beta D$ captures the effect of price differences between garage and street parking. So, given information on parking duration and choices made by individual drivers, one can estimate $\alpha$ and $\theta$. The driver is indifferent between street and garage parking when the duration $d^{*}=-\alpha / \theta$. We will refer to $d^{*}$ as the 'indifference parking duration'. ${ }^{15}$

By 'willingness to pay for street parking', $\mathrm{WTP}_{\mathrm{s}}$, we refer to the monetary value that the driver attached to parking on-street, compared to the alternative of garage parking. ${ }^{16}$ It is defined as $\left[U_{s}(d)-U_{g}(d)\right] /\left[-\partial U_{s}(d) / \partial p_{g}(d)\right]$. Given (2), it can be written as:

$$
W T P_{s}=-\alpha / \beta=-\alpha D / \theta \text {. }
$$

Hence, the willingness to pay for street parking can be derived given estimates of $\alpha$ and $\beta$.

\subsection{Estimation procedure}

We will use probit models to estimate $\alpha$ and $\beta$. There are several reasons to expect that duration is endogenous. First, we have two standard reversed causation arguments. When garage parking entails, on average, a longer walking distance to the final destination (e.g., a shop), a driver will park longer in a garage, ceteris paribus. In addition, when parking duration

\footnotetext{
${ }^{14}$ Note that (4) can be easily generalised. It may for example be the case that $\alpha$ is weather specific. So, in the empirical analysis we will control for weather conditions. It may also be the case that $\alpha$ and $\beta$ depend on the type of activity at the destination, which differ with the time of parking. So, we will estimate different models for different hours and days (see the sensitivity analysis).

${ }^{15}$ When the distribution of $\varepsilon$ is symmetric (which is true for the normal distribution), then it holds that $\operatorname{Prob}(\varepsilon>0)=0.5$. When $\mathrm{P}_{\mathrm{s}}=\mathrm{P}_{\mathrm{g}}=0.5$, the driver is indifferent where to park.

${ }^{16} \mathrm{So}, W T P_{s}$ is equal to the tariff difference at the indifference duration, $d^{*} D$.
} 
is elastic with regard to price, drivers will decrease their duration when parking on-street (which is more expensive in the current application). Both reasons suggest that ignoring endogeneity will induce a negative bias of the estimated price effect on the probability of parking on-street.

However, other considerations suggest the opposite bias. Drivers who park in garages have to pay afterwards, so in this case we observe the actual parking duration, which may differ from the intended parking duration. ${ }^{17}$ Furthermore, in many cities (including the city we focus on), curbside meters accept coins but do not return any, which creates errors in payment. So, drivers may pay for a longer duration than intended. For street parking, it may also sometimes occur that the parking duration of one driver is observed as two different parking durations.

We deal with these endogeneity issues by using an IV approach. As an instrument, we use the average duration of both street and garage parking in the whole area at the time of parking. ${ }^{18}$ This instrument not only solves the reversed causality bias, it also addresses measurement issues of duration. ${ }^{19}$

\section{The data}

We employ information on all paid parking transactions during shopping hours (9am to 6pm) that took place in the Almere CBD in $2009 .{ }^{20}$ We have information on: (a) the time of inflow, (b) the price paid and (c) parking location. Based on the price paid, we calculated the implied parking duration.

\footnotetext{
${ }^{17}$ The difference between actual and intended parking duration is important, because drivers choose the parking type based on the intended duration. When the difference between intended and actual duration is random, which seems plausible, we get a standard measurement-in-error bias argument, so ignoring endogeneity will induce a bias towards zero.

${ }^{18}$ To be precise, we use the average duration over a 60 -minutes time interval.

${ }^{19}$ The average duration is calculated for hundreds of car drivers, so measurement error is absent.

${ }^{20} \mathrm{We}$ do not have information on drivers with on-street parking permits and we exclude drivers with season tickets in garages.
} 
We make several data selections. First, we exclude Sundays and Holidays (e.g. Christmas), which are non-paid days. Second, we are interested in parking choices when garage and street parkings are not full, so when the observed parking choice is generally the preferred option (conditional on price and location). So, we exclude Saturdays, when garages are more likely to be full, and focus on weekdays only. ${ }^{21}$ Third, to ensure that drivers pay for the full duration of parking, we select drivers who park between 9am and 4pm with durations up to 120 minutes (parking is usually free after $6 \mathrm{pm}$ ). ${ }^{22}$ Fourth, we exclude parking locations where garage parking is usually closer to potential destinations than street parking (these locations are not on the map in Figure 1). Hence, we exclude parkings near a shopping-mall and hospital with integrated garages (and only very few street parking). ${ }^{23}$

Given these selections, we have information on 475,899 parking transactions over 258 days. In the area we focus on, there are 3,526 parking spaces of which 2,232 are in a garage and 1,294 are on-street (a share of 37 percent).

Street and garage parking fees are regulated by the local government. On-street, we observe parking durations in intervals of 20 minutes, whereas for garage parking the interval is 19 minutes. For convenience, we assume that drivers park the maximum duration within the interval. ${ }^{24}$ Conditional on above selections, the average parking duration is 52 minutes and 43 percent of drivers park on-street. For the first 120 minutes of parking, garage prices are $€ 0.50$

\footnotetext{
${ }^{21}$ During the period of observation, parking supply has been constant. This is important to emphasise because changes in local supply of parking are not uncommon in many cities and are usually difficult to measure.

${ }^{22}$ Another advantage of focusing on parking durations up to 120 minutes is that we do not have to worry that the estimated coefficients are mainly determined by relatively few observations of extremely long street parking durations (only 4 percent of street parking is for longer than 120 minutes). In the sensitivity analysis, we show that our results are robust if we also include longer parking durations.

${ }^{23}$ In these zones, garage parking is the preferred option for (most) drivers (i.e., cheaper and closer by).

${ }^{24}$ A sensitivity test using the mean duration within the interval (rather than the maximum) generates essentially identical results, except that the indifference duration becomes half an interval shorter (about 10 minutes).
} 
per 19 minutes and street prices are $€ 0.70$ per 20 minutes, so street parking is 33 percent more expensive. ${ }^{25}$

In our data, the share of street parking strongly falls with duration. As shown in Table 1, 55 percent of drivers with a duration shorter than 41 minutes park on-street. However, of drivers with a duration longer than 120 minutes, only 9 percent park on-street. Table 1 furthermore provides duration frequencies. It illustrates, for example, that 47 percent of drivers park shorter than 41 minutes. For those who park on-street, this is even 69 percent. As emphasised above, it also shows that of the drivers who park on-street, only 4 percent park longer than 120 minutes. Of drivers who park in garages, 24 percent park longer than 120 minutes.

Table 1: Share street parking and frequencies per duration category

\begin{tabular}{lccc|cc}
\hline Duration & $<41$ minutes & $41-80$ minutes & $81-120$ minutes & $\geq 121$ minutes & Total \\
\hline Share street parking & 0.55 & 0.32 & 0.21 & 0.09 & 0.43 \\
\hline Frequencies & & & & & \\
\hline & 0.47 & 0.24 & 0.13 & 0.16 & 1.00 \\
Street & 0.69 & 0.20 & 0.07 & 0.04 & 1.00 \\
Garage & 0.34 & 0.26 & 0.16 & 0.24 & 1.00 \\
\hline
\end{tabular}

One complication is that during the period of observation, curbside meters did not give change in return, so payments that are not multiples of exactly $€ 0.70$ imply excess payment. In our data, 66 percent of street parking transactions incur excess payment. The average excess payment is $€ 0.23$ (which is non-negligible, as it amounts to about 14 percent of the average payment on-street). When drivers are aware of this excess payment, this may be seen as an additional anticipated transaction cost for street parking. However, it seems likely that the excess payment is higher for drivers who park for the first time and who are not aware of

\footnotetext{
${ }^{25}$ After two hours of parking, the marginal price of garage parking is zero up to 4 hours of parking, so street parking is relatively more expensive for durations between 120 and 240 minutes. For the first 10 minutes of parking, garage parking is free. We will come back to this complication in the sensitivity analysis.
} 
this. So, the average excess payment is likely a maximum of the anticipated transaction costs for street parking. For garage parking, machines do return change, so there is hardly any excess payment (more than 99.9 percent of drivers pay in multiples of $€ 0.50$ ).

\section{Empirical Results}

\subsection{Main results}

We have estimated several probit models on the choice between street and garage parking. We focus on the effect of parking duration. We control for heterogeneity in demand by including five day-of-the-week dummies (Monday, .. , Friday), 52 week dummies and 27 time of the day dummies (measured in quarters of an hour). Furthermore, we control for weather conditions by including 7 temperature Celsius interval dummies $(<0,0-5, . ., 20-25,>25)$. In addition, to control for snowfall, we include a dummy which is constructed by interacting temperatures below 2 degrees Celsius with precipitation. ${ }^{26}$ Our instrument (i.e., the average parking duration, on-street and in garages) appears to be strong (the F-test is 3,660, so far above the minimum of 10 usually recommended). ${ }^{27}$

Table 2 reports the estimated effect of parking duration in minutes, $\theta$, on the probability that a driver parks on-street (rather than in a garage) for several specifications. It also reports the mean $\alpha$ which is the intercept $\alpha$ given the mean values of the control variables. In column [1], we show the results of a standard probit specification where we only include duration $d$ (not instrumented, no control variables). The coefficient $\theta$ is equal to 0.0115 (s.e. 0.0001 ) and $\alpha$ is equal to 0.402 (s.e. 0.0037 ). ${ }^{28}$ When we control for weather

\footnotetext{
${ }^{26}$ When it rains, car drivers are thought to prefer to park in a garage rather than on-street, because in a garage one may leave the car without getting wet. Weather may also influence parking durations, for example in the event that people who go shopping go home earlier when it rains. Not taking these weather influences into account may therefore potentially result in an omitted variable bias. Weather data are obtained via the Royal Netherlands Meteorological Institute (KNMI).

${ }^{27}$ This instrument follows almost exactly a normal distribution with a mean of 49.8 and a standard deviation of 3.8 (1,806 unique hourly observations).

${ }^{28}$ As a robustness check we have also bootstrapped the standard errors of the estimates [1-4]. This generates almost identical standard errors.
} 
conditions (see [2]) and when we also include time-, day-, and week dummies (see [3]), these results hardly change. ${ }^{29}$ In column [4], $d$ has been instrumented. This results in a value of $\theta$ equal to -0.0166 (s.e. 0.0007 ), which demonstrates that $\theta$ is biased towards zero when duration is not instrumented. The estimated value of $\alpha$ in column [4] is also considerably higher and is equal to 0.661 . The latter IV estimate is our preferred estimate. Henceforth, we focus on the implications of this estimate.

Table 2: Probability of street parking.

\begin{tabular}{|c|c|c|c|c|}
\hline & $\begin{array}{c}{[1]} \\
\text { Probit }\end{array}$ & $\begin{array}{c}{[2]} \\
\text { Probit }\end{array}$ & $\begin{array}{c}{[3]} \\
\text { Probit }\end{array}$ & $\begin{array}{c}{[4]} \\
\text { IV probit }\end{array}$ \\
\hline Duration in minutes, $\theta$ & $\begin{array}{c}-0.0115^{* * *} \\
(0.0001)\end{array}$ & $\begin{array}{c}-0.0115 * * * \\
(0.0001)\end{array}$ & $\begin{array}{c}-0.0114 * * * \\
(0.0001)\end{array}$ & $\begin{array}{c}-0.0166 * * * \\
(0.0007)\end{array}$ \\
\hline Time dummies (27) & No & No & Yes & Yes \\
\hline Day dummes (5) & No & No & Yes & Yes \\
\hline Week dummies (52) & No & No & Yes & Yes \\
\hline Weather dummies (9) & No & Yes & Yes & Yes \\
\hline$\alpha$ & $\begin{array}{c}0.4018 * * * \\
(0.0037)\end{array}$ & $\begin{array}{c}0.4015^{* * *} \\
(0.0037)\end{array}$ & $\begin{array}{c}0.3961 * * * \\
(0.0037)\end{array}$ & $\begin{array}{c}0.6608 * * * \\
(0.0350)\end{array}$ \\
\hline Observations & 475,899 & 475,899 & 475,899 & 475,899 \\
\hline Level of $d$ (minutes) & \multicolumn{4}{|c|}{ Probability } \\
\hline 5 & 0.6347 & 0.6346 & 0.6327 & 0.7183 \\
\hline 30 & 0.5226 & 0.5225 & 0.5216 & 0.5647 \\
\hline 60 & 0.3866 & 0.3865 & 0.3867 & 0.3687 \\
\hline 90 & 0.2633 & 0.2632 & 0.2644 & 0.2024 \\
\hline 120 & 0.1640 & 0.1639 & 0.1656 & 0.0916 \\
\hline Level of $d$ (minutes) & \multicolumn{4}{|c|}{ Marginal effect of $d$} \\
\hline 5 & -0.0043 & -0.0043 & -0.0043 & -0.0056 \\
\hline 60 & -0.0044 & -0.0044 & -0.0044 & -0.0063 \\
\hline 120 & -0.0028 & -0.0028 & -0.0028 & -0.0027 \\
\hline Indifference duration & $\begin{array}{c}34.9453 * * * \\
(0.1796)\end{array}$ & $\begin{array}{c}34.9304 * * * \\
(0.1797)\end{array}$ & $\begin{array}{c}34.7426 * * * \\
(0.1821)\end{array}$ & $\begin{array}{c}39.7895 * * * \\
(0.4850)\end{array}$ \\
\hline
\end{tabular}

Note: robust standard errors; $\alpha$ has been adjusted to the mean value of control dummies; ${ }^{* * *}$ $\mathrm{p}<0.001$

The implied probability that an individual parks on-street is reported in the same table for different parking durations. The probability of parking on-street is 0.72 given a duration of

\footnotetext{
${ }^{29}$ As an aside, we find that cold weather and rain increase the probability of garage parking. Both effects are significant at the 99 percent level in all specifications. The effect of snow is not significant in specifications [3] and [4].
} 
5 minutes, but is reduced to merely 0.09 given a duration of 120 minutes. It appears that drivers are indifferent given a parking duration of 40 minutes (s.e. 0.48 minutes). ${ }^{30}$

The implied marginal effects of parking duration (in minutes) on the choice of parking on-street is about -0.006 during the first hour, and drops to -0.003 for longer parking durations. So, during the first hour, the marginal effect of parking duration in hours on the probability of street parking is about -0.36 . Because the hourly parking price difference is about $€ 0.52$, the implied marginal effect of the street price (in euros) on the probability of street parking, conditional on the garage price, is equal to -0.69 (i.e., $-0.36 / € 0.52$ ). Given a parking duration of one hour, the price of street parking is about $€ 2.10$, and the probability to park on-street is equal to 0.37 (see [4]). This suggests that if the price of street parking increases by one euro, so by 48 percent, the demand for street parking falls by 186 percent (i.e., - -0.69 / 0.37). Hence, given a parking duration of one hour, the price elasticity of the street parking share is -3.88 . This implies that the demand for parking on-street is rather elastic given the presence of garage parking in the same area, which makes sense as both parking types are close substitutes. Our estimates also imply that the elasticity is much smaller for short durations. For example, given a parking duration of 20 minutes, the price of street parking is $€ 0.70$ whereas the average probability to park on-street is 0.63 , implying that the price elasticity of the street parking share is only $-0.81 .^{31}$

We believe this is an obvious but important insight: for short parking durations, the demand for parking is rather price inelastic even when there are cheaper parking locations only slightly farther away. This result is also relevant to institutional contexts common to, for example, the US where street prices tend to be low (or even zero), so that drivers will cruise for parking (e.g. Arnott and Inci, 2006). In this context, behaviour of commercial parking

\footnotetext{
${ }^{30}$ The standard error of the indifference parking duration is calculated using the delta method.

${ }^{31}$ At a parking duration of 20 minutes, the marginal effect of parking duration in hours is -0.38 , and the probability that a driver parks on-street is equal to 0.63 . The marginal effect of a one euro price increase on demand is then -0.73 (i.e., $0.38 / € 0.52$ ). So, when price increases by 143 percent (i.e., $€ 1.00 / € 0.70$ ), demand increases by 116 percent (i.e., $-0.73 / 0.63$ ), implying an elasticity of -0.81 .
} 
operators have been studied under the assumption that they have local monopolistic power (Arnott, 2006; Arnott and Rowse, 2009). In general, monopolistic markup rules indicate that the ratio between the operator's profit margin and garage parking price is inversely proportional to the price elasticity of demand. So, when the demand for parking is elastic, commercial parking operators have less pricing power. Because our results imply that the demand for parking is rather inelastic for short parking durations, it seems plausible that commercial parking operators would have substantial pricing power for drivers with short park durations. This is particularly relevant because short durations are common. ${ }^{32}$

Using equation (7), the willingness to pay a premium for street parking is $€ 0.35$ (with a standard error of 0.003). However, (7) ignores the earlier noted complication of excess payment for street parking, as curb meters do not return change. Given the mean excess payment of $€ 0.23$ for street parking, the drivers' willingness to pay a premium for street parking may be as high as $€ 0.58$ (i.e., $€ 0.35+€ 0.23$ ). When we assume a car drivers' value of walking time of $€ 5.00$ per hour (about one third of the wage, in line with Axhausen and Polak, 1991), and ignore other reasons why drivers may opt for either parking type, our results imply that drivers save about $4-7$ minutes when parking on-street. This seems a reasonable result in our current application. Our finding that drivers are willing to pay a premium to street parking also implies that there are good economic reasons to have a onstreet parking premium policy.

\subsection{Parking choices in hypothetical pricing schemes}

Figure 2 provides information about the probability that a driver chooses to park on-street for three hypothetical pricing schemes, which are compared to the current pricing scheme. This is possible when the estimated parameters $\alpha$ and $\beta$ are structural in the sense that they do not

\footnotetext{
${ }^{32}$ The median parking duration is 57 minutes in the Almere CBD. Given our selection of parking durations up to 120 minutes, the median duration is 40 minutes.
} 
change for different pricing schemes. For the hypothetical pricing schemes, we ignore restrictions in parking supply, so we assume that parking supply is infinite (ignoring cruising for parking) and assume that total demand for parking is perfectly inelastic, so neither drivers' decision to park, nor their durations, are influenced by changes in pricing. ${ }^{33}$

Figure 2 shows the results for the current pricing scheme, so when there is an on-street parking premium. The probability of street parking falls from 0.75 when the duration is (close to) zero to 0.50 when the duration is 40 minutes, and to 0.09 when the duration is 120 minutes. In the first hypothetical scheme, we suppose that street and garage parking have the same price. In this case, parking choice does not depend on duration, so sorting based on duration is eliminated, and the probability of street parking increases to 0.75 for all durations. The increase is particularly large for long durations, which have a small street parking probability in the current scheme.

In the second hypothetical scheme, street parking is assumed to be 33 percent cheaper than garage parking (so there is a garage parking premium). The probability of street parking is then 0.91 given a duration of 40 minutes, and almost 1 for a duration of 120 minutes. In the third hypothetical scheme, street parking is free and garage parking prices remain the same (i.e., $€ 0.50$ per 20 minutes). The probability that a driver chooses to park on-street is then essentially 1 for a driver with a parking duration of at least 40 minutes. For the last two hypothetical schemes, drivers do sort based on duration, but not in a way that seems to encourage efficient use of parking space: those with longest durations are more likely to choose street parking which is, on average, more nearby. Hence, Figure 2 illustrates that drivers with long parking durations react strongly to even modest changes in the pricing scheme, whereas drivers with short durations have rather inelastic demand.

\footnotetext{
${ }^{33}$ Note that if overall parking demand is elastic, the hypothetical pricing schemes that we present in Table 3 and Figure 2 yield an underestimate of demand for on-street parking.
} 


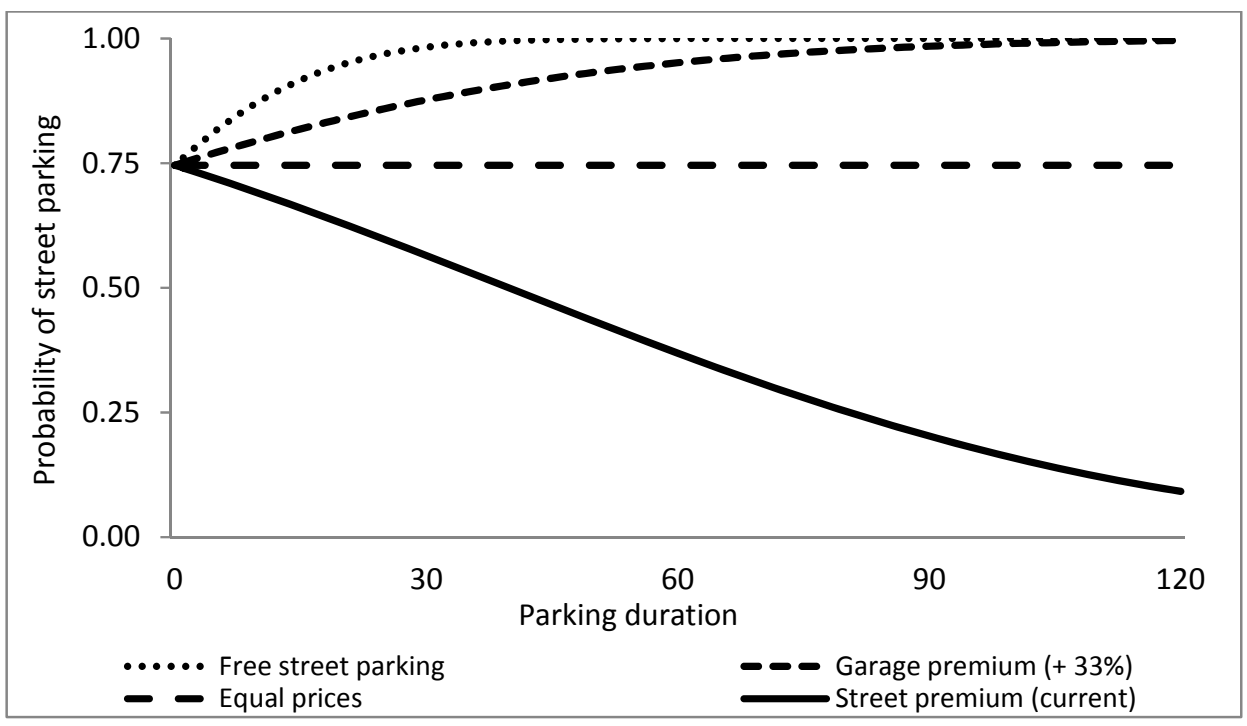

Figure 2: The probability that a driver chooses to park on-street (for hypothetical pricing schemes)

The latter results have important implications for the street inflow rate, as well as the stock of cars parked on-street. Based on Figure 2, Table 3 presents the implied percentage change in the daily-average hourly inflow into street parking, as well as the stock of cars parked on-street (drivers with season tickets and permits are excluded). ${ }^{34}$ It shows that a reduction in street prices (relative to garage prices) strongly increases the inflow into street parking, but it results in an even stronger increase in the stock of cars parked on-street. ${ }^{35}$ For example, if street parking and garage parking would be equally expensive, the street inflow would increase by about 67 percent, but the stock of cars parked on-street increases by 127 percent. ${ }^{36}$ Given the assumption of inelastic total demand, corresponding decreases are found for garage parking.

\footnotetext{
${ }^{34}$ We have calculated the hourly-average inflow rate and stock, for each hour of the day, but for convenience, we present only the daily-average results.

${ }^{35}$ The stock particularly increases because drivers with long durations have a disproportionally large influence on the stock of cars parked on-street.

${ }^{36}$ Note that Table 3 slightly underestimates the changes in parking stock, because we exclude drivers with durations longer than 120 minutes.
} 
Table 3: Street inflow and stock (for current and hypothetical parking schemes)

\begin{tabular}{lcc}
\hline Street premium of $33 \%$ (current) & Inflow & Stock \\
Equal prices & & \\
Garage premium of $33 \%$ & $+67 \%$ & $+127 \%$ \\
Street for free & $+105 \%$ & $+193 \%$ \\
\hline
\end{tabular}

Note: estimates are based on average hourly inflow between 9:15am -4:00pm.

\section{Sensitivity analysis}

We have re-estimated the model including fixed effects for all 258 days (rather than including 52 week and 5 weekday dummies). This leads to results almost identical to Table $2 .{ }^{37}$ Hence, our results are very robust regarding unobserved day-specific heterogeneity. Table 4 provides the results of a number of other sensitivity tests.

Drivers who leave a garage within 10 minutes after arrival do not have to pay for parking, which may, at least theoretically, result in a bias in the estimates. ${ }^{38}$ In addition, drivers who park very shortly on-street are also less likely to pay for parking (they may park illegally, or leave the car with a passenger inside, for example). So, more in general, information about short parking durations may be unreliable. Hence, we have re-estimated the model, excluding observations for less than 20 minutes. It appears that the results change somewhat, resulting in a slightly longer indifference parking duration (i.e., 47 minutes rather than 40 minutes). In addition, we have re-estimated the model including drivers with parking durations up to 240 minutes (rather than 120 minutes, as in Table 2). It appears that this does not influence our results much: the indifference duration is essentially the same.

As a robustness check, we have also re-estimated the model for different weekdays and for different parts of the day. We do not find any evidence that drivers who park during other parts of the day vary in terms of their indifference duration. Variations in the indifference duration between weekdays are larger though, not because $\theta$ differs between

\footnotetext{
${ }^{37}$ Results can be received upon request.

${ }^{38}$ Note that drivers who are in a garage for less than 10 minutes likely do not have parked and left the garage prematurely, for example because they changed their minds or were not able to find a place.
} 
days, but because $\alpha$ differs between days. It seems that particularly on Monday drivers prefer to park on-street. One explanation for this result is the presence of driver heterogeneity: on Monday mornings, many stores are closed, resulting in a higher share of business related trips. Drivers on business trips may have a higher probability of street parking, because they tend to have a higher value of walking time than drivers who go shopping.

Table 4: Sensitivity tests

\begin{tabular}{lcccc}
\hline & No. obs. & $\alpha($ mean) & $\theta$ & Indif. dur. \\
\hline Durations 21-120 minutes & 325,236 & $0.937^{* * *}$ & $-0.012^{* * *}$ & $46.90^{* * *}$ \\
Durations 0-240 minutes & & $(0.077)$ & $(0.001)$ & $(1.17)$ \\
& 543,059 & $0.453^{* * *}$ & $-0.011^{* * *}$ & $41.304^{* * *}$ \\
\hline Mondays & & $(0.0213)$ & $(0.000)$ & $(0.90)$ \\
& 74,724 & $0.695^{* * *}$ & $-0.014^{* * *}$ & $49.81^{* * *}$ \\
Tuesdays & & $(0.100)$ & $(0.002)$ & $(0.78)$ \\
& 87,029 & $0.434^{* * *}$ & $-0.012^{* * *}$ & $37.63^{* * *}$ \\
Wednesdays & & $(0.109)$ & $(0.002)$ & $(2.42)$ \\
& 127,382 & $0.400^{* * *}$ & $-0.012^{* * *}$ & $32.13^{* * *}$ \\
Thursdays & & $(0.107)$ & $(0.002)$ & $(3.36)$ \\
& & $0.495^{* * *}$ & $-0.013^{* * *}$ & $39.23^{* * *}$ \\
Fridays & 86,886 & $(0.092)$ & $(0.002)$ & $(1.71)$ \\
& & $0.355^{* * *}$ & $-0.011^{* * *}$ & $31.22^{* * *}$ \\
\hline 9:00am - 12:00pm & 99,878 & $(0.099)$ & $(0.002)$ & $(3.21)$ \\
& & $0.443^{* * *}$ & $-0.012^{* * *}$ & $38.04^{* * *}$ \\
12:00pm - 2:00pm & 165,700 & $(0.068)$ & $(0.001)$ & $(1.50)$ \\
& & $0.621^{* * *}$ & $-0.016^{* * *}$ & $39.12^{* * *}$ \\
2:00pm -4:00pm & 155,958 & $(0.081)$ & $(0.001)$ & $(1.37)$ \\
& & $0.753^{* * *}$ & $-0.019^{* * *}$ & $39.92^{* * *}$ \\
& \multirow{2}{*}{154,241} & $(0.061)$ & $(0.001)$ & $(0.68)$ \\
\hline
\end{tabular}

Note: the constant has been adjusted to the mean value of control dummies; ${ }^{* * *} \mathrm{p}<0.001$

\section{Conclusion}

The current paper is motivated by a series of theoretical papers in the economic literature on parking (e.g. Arnott and Rowse, 2009; Calthrop and Proost, 2006) as well as the works by Shoup $(2005$; 2006), which all focus on optimal pricing of street parking. An important issue emphasised in the current paper is that street and garage parking are usually not perfect substitutes, because of spatial differences in parking supply. For example, when the supply of 
street parking is ubiquitous but garage parking is discretely supplied over space, many drivers will have a preference for street parking, which is, on average, to their final destination.

Our results indicate that for longer durations, car drivers are rather sensitive to small (street and garage) price differences, but this is not the case for shorter durations. For example, given a parking duration of one hour, we find that the price elasticity of the street parking share is -3.9 , but for parking durations of 20 minutes, it is only -0.8 . This result is also relevant to other institutional contexts, common in the US, for example, where street prices are usually extremely low (or even zero), and where drivers frequently cruise for parking. Our results, particularly for shorter durations, support the idea developed in Arnott (2006) and Arnott and Rowse (2009) that commercial parking operators have monopolistic pricing power.

In the theoretical literature, it is emphasised that parking duration is endogenously chosen (e.g. Glazer and Niskanen, 1992). ${ }^{39}$ Our results imply that it is also relevant to acknowledge that drivers strongly differ in terms of (self-chosen) parking duration, so there is a distribution of parking durations. In general, conditional on the distribution of parking durations of otherwise homogeneous car drivers, the average walking distance to the final destination is minimised when drivers with longer parking durations park at locations that are farther away from the final destinations. ${ }^{40}$ So, in the context where garage parking is discretely supplied over space whereas street parking is ubiquitous, it is usually preferred that street parking be used by car drivers with short parking durations. The latter equilibrium outcome, where drivers with short durations sort themselves into street parking, can be

\footnotetext{
${ }^{39}$ The main exception is the duration of parking by commuters, which is determined by the work hours duration.

40 We ignore here any systematic relation between the parking duration and the location of the drivers' final destinations (see, similarly, Arnott, 2006).
} 
achieved by ensuring that street parking is somewhat more expensive than garage parking per unit of time, so there must be an on-street premium. ${ }^{41}$

\section{References}

ADB (2010), Parking Policy in Asian Cities, Asian Development Bank.

Anderson, S.P. and A. de Palma (2004), The economics of pricing parking, Journal of Urban Economics, 55, 1-20.

Arnott, R., A. de Palma and R. Lindsey (1991), A temporal and spatial equilibrium analysis of commuter parking, Journal of Public Economics, 45, 301-335.

Arnott, R. (2006), Spatial competition between parking garages and downtown parking policy. Transport Policy, 13, 458-460.

Arnott, R. and E. Inci (2006), An integrated model of downtown parking and traffic congestion, Journal of Urban Economics, 60, 418-442.

Arnott, R. and J. Rowse (2009), Downtown parking in auto city. Regional Science and Urban Economics, 39, 1-14.

Arnott, R., E. Inci and J. Rowse (2012), Dowtown parking and traffic congestion a diagrammatic exposition. Mimeo, University of California.

Axhausen, K.W. and J.W. Polak (1991), Choice of parking: stated preference approach. Transportation, 18 (1), 59-81.

Calthrop, E. (2001), Essays in Urban Transport Economics, PhD Thesis 151, Leuven.

\footnotetext{
${ }^{41}$ The optimal level of this premium depends on the distribution of durations and the supply of street and garage parking. As we do not have detailed information about parking by drivers with residential parking permits and season tickets, we are not able to derive the optimal level here.
} 
Calthrop E. and S. Proost (2006), Regulating on-street parking. Regional Science and Urban Economics, 36, $29-48$.

Gillen, D.W. (1978), Parking policy, parking location decisions and the distribution of congestion. Transportation, 7, 69-85.

Golias, J., G. Yannis, and M. Harvatis (2002), Off-street parking choice sensitivity. Transportation Planning and Technology, 25, 333-348.

Hasker, K. and Inci, E (2011), Free parking for all in shopping malls, Sabanci University, Working Paper ID:SU_FASS_2010/0004.

Hensher, D.A. and J. King (2001), Parking demand and responsiveness to supply, pricing and location in the Sydney central business district. Transportation Research A, 35A, 177196.

Kelly, J.A. and J.P. Clinch (2006), Influence of varied parking tariffs on parking occupancy levels by trip purpose. Transport Policy, 13, 487-495.

Kelly, J.A. and J.P. Clinch (2009), Temporal variance of revealed preference on-street parking price elasticity. Transport Policy, 16, 193-199.

Glazer, A. and E. Niskanen (1992), Parking fees and congestion, Regional Science and Urban Economics, 22, 123-132.

Shoup, D.C. (2005), The High Costs of Free Parking, American Planning Association, Chicago, IL.

Shoup, D.C. (2006), Cruising for Parking, Transport Policy, 13, 479-486.

Van der Goot, D. (1981), A model to describe the choice of parking places. Transportation Research, 16A (2), 109-115. 
Van Ommeren, J.N., D. Wentink, and J.E.C. Dekkers (2011), The real price of parking policy. Journal of Urban Economics, 70, 25-31.

Van Ommeren, J.N., D. Wentink, and P. Rietveld (2012), Empirical evidence on cruising for parking. Transportation Research Part A: Policy and Practice, 46 (1), 123-130.

Van Ommeren, J.N and D. Wentink (2012), The (hidden) costs of employer parking policies. International Economic Review, forthcoming.

Vickrey, W.S. (1969), Congestion theory and transport investment. American Economic Review, 59 (2), 251-260. 